\title{
GÉNERO, CONVENTO Y ESCRITURA: LA POESÍA DE SOR LEONOR DE OVANDO EN EL CARIBE COLONIAL
}

\author{
RAÚL MARRERO-FENTE \\ University of Minnesota \\ rmarrero@umn.edu
}

\section{RESUMEN}

En este ensayo propongo una nueva lectura de la obra de Sor Leonor de Ovando para entender su importancia en la cultura del Caribe colonial. La tesis principal de mi trabajo es que la lectura antológica, que en su momento fue una labor de rescate, convirtió la figura y la obra de la monja en un tópico anacrónico. En mi opinión, hay que comparar los poemas de Eugenio de Salazar y de Leonor de Ovando para ofrecer una valoración que preste atención a los aspectos más novedosos de la poesía de Sor Leonor de Ovando.

Palabras clave: Sor Leonor de Ovando, Caribe colonial, Eugenio de Salazar.

\section{ABSTRACT}

In this paper I propose a new reading of the work of Sister Leonor de Ovando to understand its importance in Colonial Caribbean culture. The main thesis of my work is that the anthology that once was a recovery effort, made the figure and work of the nun an anachronistic topic. In my opinion we need to compare the poems of Eugenio de Salazar and Leonor de Ovando to provide an assessment of the most innovative aspects of her poetry.

Keywords: Sister Leonor de Ovando, colonial Caribbean, Eugenio de Salazar.

En este ensayo propongo una nueva lectura de la obra de Sor Leonor de Ovando para entender mejor su lugar dentro de la cultura de su época. La tesis principal de mi trabajo es que la lectura antológica que en su momento fue una labor de rescate, convirtió la figura y la obra de Sor Leonor de Ovando en un tópico anacrónico. Este lugar común en el discurso crítico contribuye a reiterar estereotipos y lecturas mecanicistas dentro del contexto de la producción cultural del Caribe en el siglo XVI.

Desde la edición pionera de Marcelino Menéndez Pelayo, en la «Introducción» a la Antología de poetas hispano-americanos publicada en Madrid en 1892, donde da a conocer los poemas de Sor Leonor de Ovando, pasando por los estudios de Pedro Henríquez Ureña en La cultura y las letras coloniales en Santo Domingo de 1936, hasta trabajos más recientes vemos la reiteración de una labor editorial que insiste en una imagen fragmentaria de la poesía de la monja caribeña. Estudios actuales que reconocen el carácter competitivo de su poesía siguen reproduciendo los poemas de la monja, sin tomar en cuenta el contexto de su producción, en especial su condición de texto que dialoga con la poesía de Eugenio de Salazar, que es la que motiva la aparición de los poemas, escritos siempre
Raúl Marrero-Fente

Profesor titular de literatura hispanoamericana en la Universidad de Minnesota. Es autor de Espejo de paciencia de Silvestre de Balboa (2010), Bodies, Texts, and Ghosts: Writing on Literature and Law in Colonial Latin America (2010), Epic, Empire and Community in the Atlantic World: Silvestre de Balboa's Espejo de paciencia (2008), Épica, imperio y comunidad en el Nuevo Mundo: Espejo de paciencia de Silvestre de Balboa (2002), Playas del árbol: Una visión trasatlántica de las literaturas hispánicas (2002), La poética de la ley en las Capitulaciones de Santa $\mathrm{Fe}$ (2000), y Al margen de la tradición: Relaciones entre la literatura colonial y peninsular de los siglos XV, XVI y XVII (1999).

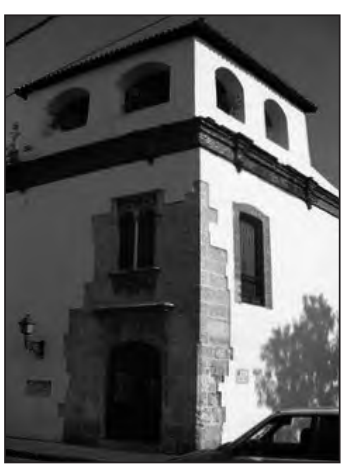

Casa de Francisco Tostado de la Peña (1505). Santo Domingo.

Género, convento y escritura: la poesía de Sor Leonor de Ovando en el Caribe colonial

RAÚL MARRERO-FENTE 


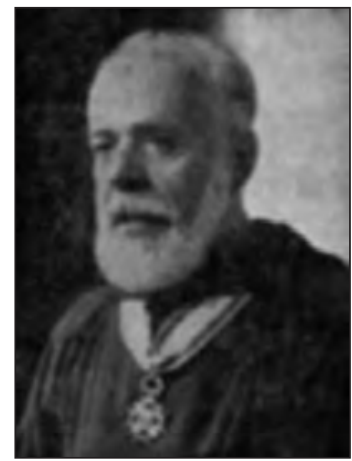

Cipriano de Utrera (Utrera, 1886-1958).
Género, convento y escritura: la poesía de Sor Leonor de Ovando en el Caribe colonial

RAÚL MARRERO-FENTE como respuestas de la monja a su interlocutor poético. Aunque Menéndez Pelayo señaló que las composiciones de la monja aparecían dentro de la Silva de poesía de Eugenio de Salazar, la mayoría de las lecturas solamente indican la condición de poesía de ocasión y la competencia de la misma, pero no explican la génesis dialógica de los poemas. Los escasos trabajos críticos que mencionan el carácter de intercambio y de diálogo literario de los textos de Ovando se limitan a una declaración general, sin entrar en un análisis comparado de ambos autores. Hasta las antologías utilizadas en los cursos de literatura reproducen sólo los poemas de la monja, sin incluir los de Eugenio de Salazar, aunque cada poema de Sor Leonor lleve la inscripción «escrito en respuesta». En mi opinión, hay que comparar los poemas de ambos autores para ofrecer una valoración más pertinente, que preste atención a los aspectos más novedosos de la poesía de Sor Leonor de Ovando.

También los estudios biográficos dedicados a la monja continúan reiterando las mismas ideas y temas desde Menéndez Pelayo y Pedro Henríquez Ureña, pero falta una labor de investigación en los archivos españoles, en especial en el Archivo de Indias de Sevilla, que rescate documentos e información sobre el entorno vital de Leonor de Ovando. En este sentido son valiosas las investigaciones de Iride Rossi de Fiori y Rosanna Caramella sobre los conventos femeninos en La Española, y los trabajos de los historiadores Cipriano Utrera y Néstor Contín sobre el mundo colonial dominicano. Para valorar mejor la obra de sor Leonor de Ovando es imprescindible conocer las complejas relaciones entre las monjas de su convento y la orden de los Dominicos; así como el papel de las autoridades coloniales en la isla caribeña durante el siglo XVI.

El contexto de la poesía de Sor Leonor de Ovando está vinculado a su condición de monja y al espacio conventual donde crea su obra. Este espacio es el del convento de Santa Catalina de Siena y su iglesia de Regina Angelorum, fundado en La Española en 1561 (Utrera, 1951, p. 23). Como señalan las investigaciones de Utrera, el convento estaba subordinado a la autoridad de los priores provinciales de la orden de su distrito, quienes ejercían la fiscalización de las actividades en el convento. Esta relación de subordinación fue determinante en las actividades diarias de las monjas y tuvo momentos de gran significación en la vida de Sor Leonor, pero desconocemos qué impacto tuvo en su producción poética. Tampoco sabemos si la monja entregó algunos de sus poemas a las autoridades eclesiásticas de la isla. De acuerdo a las investigaciones de Utrera, Sor Leonor de Ovando tomó el hábito de monja en Santo Domingo antes de 1567 (Utrera, 1951, p. 24), y ya estaba en el convento en 1570. En ese mismo año ella es elegida superiora del mismo, después de la sustitución de la priora y superiora, causado por problemas internos en la orden de los dominicos (Utrera, 1951, p. 16). Unos años más tarde, en 1583, Sor Leonor de Ovando es elegida priora. Inmediatamente después, Sor Leonor escribe una carta al Rey solicitando ayuda económica para el convento. En 1595 y 1605 , como superiora, vuelve a escribir pidiendo fondos (Utrera, 1951, p. 22). En 1608 escribe una carta al Rey acusando al oidor de la Audiencia Manso de Contreras, por lo que entra en conflicto con el gobernador y otras autoridades eclesiásticas. Como señala Utrera:

Aunque no contamos con otros testimonios hasta hoy, llama la atención que apenas dos años después de esta persecución religiosa y secular, sor Leonor fallece en el convento de Santa Catalina hacia 1610. Fue monja de este convento por cuarenta años y murió de sesenta años, hacia 1610 (Utrera, 1951, p. 33).

La información sobre la vida y la obra de Eugenio de Salazar es más conocida gracias a las extensas investigaciones de Jaime Martínez. En 1573 Eugenio de Salazar es nombrado oidor de la Audiencia de Santo Domingo, a donde llega procedente de las islas Canarias. Dos años después es destituido de su puesto de oidor, como resultado de conflictos entre los oidores y el Presidente de la Audiencia. Entre los años 1574 y 1576, desarrolla su actividad de poeta en La Española. En ese período conoce a sor Leonor de Ovando, con quien tiene un intercambio poético que aparece recogido en la Silva. (Martínez, 2002, p. 16). Para poder valorar mejor los poemas de Leonor de Ovando y comprender la importancia de este diálogo poético, analizo los dos primeros sonetos que intercambiaron ambos poetas y que aparecen en el manuscrito de la Silva que está en la Biblioteca de la Academia de la Historia de Madrid. Reproduzco a continuación estos dos sonetos en la transcripción inédita de Jaime Martínez [p. 669]: 


\section{A LA INGENIOSA POETA Y MUY \\ RELIGIOSA OBSERUANTE \\ DOÑA LEONOR DE OUANDO, \\ PROFESSA EN EL MONASTERIO DE \\ REGINA DE LA ESPAÑOLA, \\ EUGENIO DE SALAZAR, SU MUY \\ DEUOTO Y SERUIDOR, \\ EN LA FIESTA DE LA NATIUIDAD}

\section{SONETO}

El que' ab eterno' es hijo glorioso, el hombre que' ab eterno' es Dios diuino, el que' a vestirse nuestra carne vino ardiendo' en vn amor tan amoroso;

el que nasçió en vn mundo tan penoso por recobrarnos el perdido tino

y por endereçar el mal camino

que nos lleuaba' al seno temeroso;

el que salió desnudo' y con pobreza siendo Dios rico', y padesçiendo frío sólo por dar remedio' a nuestras penas;

esse reçién nascido, que’ es Dios mío, con vos reparta de su gran riqueza

y os dé, señora', el don de pascuas buenas.

En 1574 comienza el intercambio poético entre Leonor de Ovando y Eugenio de Salazar, durante el primer año de la estancia de éste en La Española. Por la dedicatoria y el tratamiento de las normas de cortesía de la época podemos decir que Salazar usa un trato formal, pero una lectura del manuscrito permite apreciar que modificó la dedicatoria original de: «Illa. Señora» por la de «ingeniosa poeta». Es posible que el cambio ocurriera por el paso del tiempo y una mayor relación de amistad entre ambos. También refleja el trato de personas que ya eran amigas. Quizás, con el paso del tiempo, Salazar prefirió un tono más cercano y menos formal.

En el análisis de los sonetos que aparecen recogidos en el manuscrito de la Silva el soneto inicial de Salazar está dedicado al nacimiento de Jesús. En la primera estrofa, el lugar de la enunciación de la voz lírica es desde una perspectiva masculina que habla del hijo, del hombre y de un Dios masculino. Ésta termina con la mención de la figura teológica de la encarnación de Jesús, pero el punto de vista de la enunciación es patriarcal. Es notorio en la misma la ausencia de toda mención a María, la madre de Jesús; la escena del nacimiento es presentada como un fin en sí misma, sin otras referencias. El resultado es que la escena tradicional de la familia en el nacimiento cristiano queda fuera del foco del hablante, alejando la misma de la atención del lector. En el siguiente verso, también aparece una visión patriarcal de la religión porque la voz lírica presenta la imagen de Jesús,

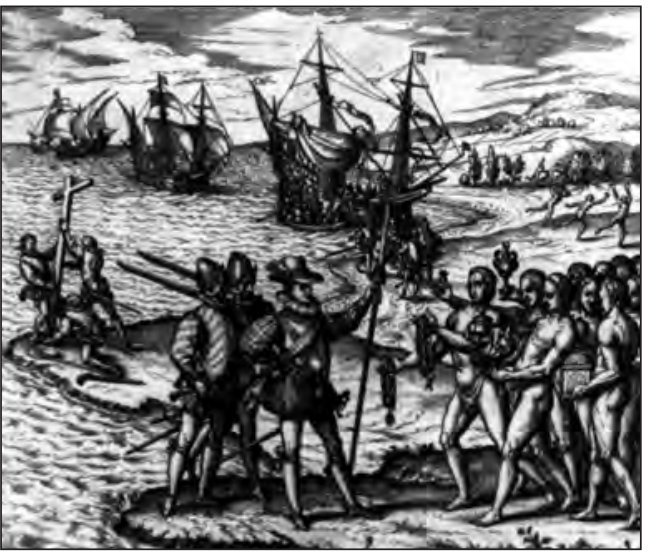

Cristóbal Colón desembarca en La Española (Grabado. Biblioteca del Congreso de Estados Unidos). como el salvador, aludiendo a caminos y rutas, que llevan hasta el relato del pecado original y por ende a la figura de Eva que es la alegoría detrás de la frase «perdido tino». Así, se construye una figura femenina negativa que desplaza la imagen de María. Aquí el discurso patriarcal logra borrar cualquier visión positiva de la mujer, ya que la alusión al pecado original, implica necesariamente la visión negativa de Eva, como actor activo en el pecado y máxima culpable. En el verso siguiente la mención a Jesús y su nacimiento es fragmentaria y sólo insiste en su relación con el padre (Dios), aunque alude a la escena de Belén, no describe la misma, ni menciona a María de Nazaret. Por último, Salazar habla del recién nacido y de su doble condición divina y humana, pero sin recordar a su madre. El poema termina como un «don de pascuas buenas», es decir como un regalo poético por el nacimiento de Jesús, abriendo de este modo la posibilidad de reciprocar, es decir, de devolver con otro poema, como vemos a continuación en la respuesta de Leonor de Ovando.

\section{A EUGENIO DE SALAZAR SU \\ ÇIERTA SERUIDORA, DOÑA LEONOR DE OUANDO, EN RESPUESTA}

\section{SONETO}

El niño Dios, la Virgen y parida, el parto virginal, el Padre' eterno, el portalico pobre y el imbierno con que tiembla' el author de nuestra vida.

sienta, señor, vuestra' alma' y, aduertida del fin de' aqueste don y bien superno
Género, convento y escritura: la poesía de Sor Leonor de Ovando en el Caribe colonial

RAÚL MARRERO-FENTE 


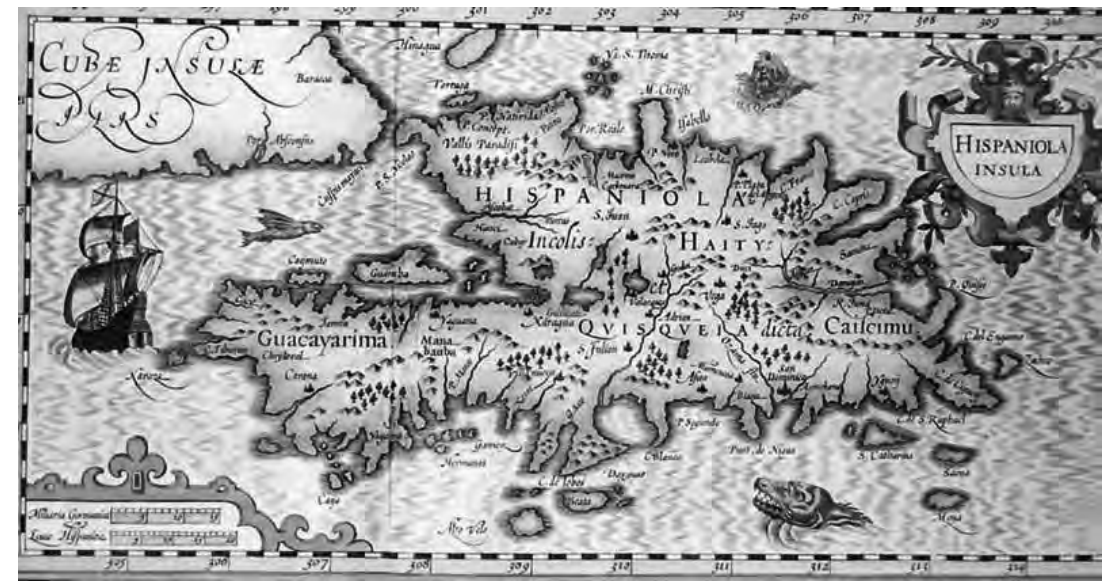

Mapa de La Española, siglo XVI.

absorta', esté' en Aquél cuyo gouierno

la tenga con su graçia guarnesçida.

Las pascuas os dé Dios qual me las distes

con los diuinos versos de' esa mano,

los quales me pusieron tal consuelo

que son alegres ya mis ojos tristes

$y$,editando bien tan soberano

el alma leuanta para' el çielo.

Sor Leonor comienza su poema con la mención a María en la figura de Theotokos, el término teológico para referirse a la encarnación de Jesús, cuando la segunda persona de la Trinidad tomó naturaleza humana en adición a su naturaleza divina. De acuerdo a la doctrina católica, el acto de la encarnación fue posible a través de la cooperación de María, quien aparece como mediadora. La frase «virgen y parida» se refiere al dogma de la «virginidad perpetua» de María, que significa que ella fue virgen antes, durante y después del nacimiento de Jesús. Este dogma fue acordado en el Concilio de Efeso en 431 y es uno de los primeros dogmas marianos. Sor Leonor de Ovando incluye además en esta estrofa la frase «pacto virginal» siguiendo el dogma de la inmaculada concepción, que de acuerdo a la doctrina católica, significa que la concepción de María fue sin pecado y que el nacimiento de Jesús es un acto milagroso.

Desde la estrofa inicial, la monja ubica la figura femenina de María de Nazaret en su rol protagónico de madre de Jesús, devolviendo a la escena del nacimiento su elemento humano. La referencia a María implica asumir un punto de vista femenino en la narración del nacimiento de Jesús, en contraste con la visión patriarcal. La maternidad de María también apela a su condición de intercesora entre Dios y los seres humanos, acercando la escena del nacimiento al mundo terrenal. Por otra parte, la mención a María en una posición importante sirve de respuesta a la alusión a Eva, como agente del pecado en el poema de Salazar. En este caso, la imagen negativa de la mujer, elaborada en el discurso patriarcal tradicional es contrastada con la imagen positiva de la mujer en la figura de María. El otro aspecto importante de la referencia de Sor Leonor en esta primera estrofa es la humanidad del niño Jesús, que sirve para igualar al mismo a todos los niños del mundo, en contraste con la imagen de Salazar, que lo sitúa en una perspectiva inalcanzable, desde el espacio divino. Esta descripción alcanza mayor sutileza cuando comparamos la de Salazar "padesçiendo frío», con la de Leonor: «y el imbierno / con que tiembla.'» La monja corporaliza al niño Jesús, quien «tiembla» de frío. Estos detalles en las descripciones que prestan más atención a los sentimientos y emociones humanas son los rasgos de diferenciación entre la voz lírica masculina y la femenina en ambos poemas. Seguidamente Leonor recuerda a Salazar el significado teológico del nacimiento de Jesús desde el punto de vista del cristianismo, es decir, como un regalo («aqueste don») para la salvación de su alma. Pero a diferencia del tratamiento que esta figura recibe en el poema de Salazar, no hay referencias a Eva o al pecado original. Es decir, la visión de Leonor es más positiva, como de un regalo sin condiciones y no lleva la connotación negativa del pecado original. La visión positiva que inaugura el poema también está presente en la segunda estrofa por medio de la figura teológica de la gracia, que Salazar recibe como buen cristiano. Según Rossi de Fiori:

El empleo de la hipérbole como también de la antítesis en este soneto se relaciona con las cualidades de la poesía, que elevan el espíritu y hacen desaparecer la pena y la angustia. El valor de la poesía es tal que necesita de un recurso hiperbólico para expresarlo (2001, p. 91).

La complejidad formal de la tercera estrofa responde además a la representación de la poesía como consolación por medio de la cual la monja participa de este diálogo con Salazar. Es el aspecto de la poesía como consolación 
otro elemento que permite un breve momento de acceso al mundo interior de Sor Leonor de Ovando. Estos intercambios poéticos trajeron, sin lugar a dudas, instantes de paz y representaron un descanso de las tareas diarias del convento. Quizás este aspecto queda reforzado en el tono personal de la voz lírica en la última estrofa del soneto. Como señala Rossi de Fiori:

Sor Leonor, incluida como protagonista de su propio soneto, sufre un cambio de ánimo como consecuencia de la fuerza vivificadora que se desprende de las composiciones de Eugenio de Salazar, por ella leídas y que tan profundamente la conmovieron. El impacto de los «divinos versos» queda apenas atenuado por las fórmulas cortesanas y por su posición de religiosa frente a un funcionario de la Corona (2001, p. 92).

El intercambio poético con Eugenio de Salazar fue, sin lugar a dudas, un ejercicio intelectual significativo para Sor Leonor. Precisamente, la última estrofa del soneto incorpora una imagen del ascenso del alma, que en una especie de rapto místico intenta la huída del mundo terrenal por medio de la poesía. La alegría causada por este intercambio de poemas, por la amistad entre poetas fue una experiencia inolvidable para la monja en la sociedad colonial. En las condiciones de la vida cultural en La Española durante el siglo XVI, la obra poética de Sor Leonor de Ovan- do constituye un testimonio importante de la búsqueda de espacios intelectuales de autoexpresión por parte de una monja caribeña.

\section{Bibliografía}

Caramella, Rosanna e Iride Rossi de Fiori (2001), El hábito y la palabra: escritura de monjas hispanoamericanas en el periodo colonial, Salta (Argentina), Editorial Biblioteca de Textos Universitarios.

Contín Aybar, Néstor (1982), Historia de la Literatura Dominicana, San Pedro de Macorís (R.D), Universidad Central del Este.

Henríquez Ureña, Pedro (1936), La cultura $y$ las letras coloniales en Santo Domingo, Buenos Aires, Imprenta de la Universidad de Buenos Aires.

Martínez, Jaime J (2002), Eugenio de Salazar y la poesía novobispana, Roma, Bulzoni.

Martínez, Jaime J. Poemas de Sor Leonor de Ovando (texto inédito)

Menéndez y Pelayo, Marcelino (1927), Antología de poetas hispano-americanos, Madrid, Tip. de la «Revista de archivos».

Rossi de Fiori, Iride (2008), La palabra oculta: monjas escritoras en la Hispanoamérica Colonial, Salta (Argentina), Ediciones Universidad Católica de Salta.

Utrera, Cipriano de (1951), Sor Leonor de Ovando, Ciudad Trujillo, Tip. Franciscana.

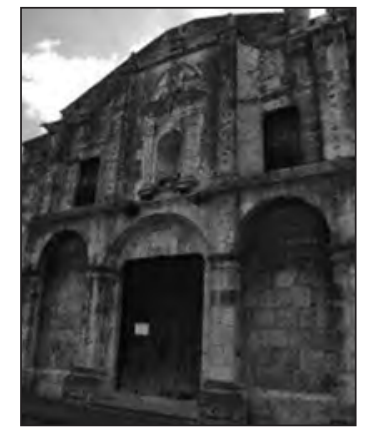

Iglesia Regina Agelorum y Convento, donde vivió Leonor de Ovando.

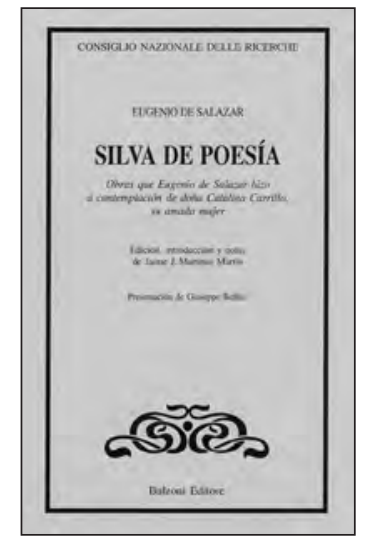

Eugenio de Salazar, Silva de Poesía. Portada. 